\title{
Feasibility of hydraulic separation in a novel anaerobic-anoxic upflow reactor for biological nutrient removal
}

\author{
R. Díez-Montero ${ }^{\mathrm{a}}$, L. De Florio ${ }^{\mathrm{a}}$, M. González-Viar ${ }^{\mathrm{a}}$, E.I.P. Volcke ${ }^{\mathrm{b}}$, I.
}

Tejero $^{\mathrm{a}^{*}}$

${ }^{a}$ Department of Science and Techniques of Water and the Environment, University of Cantabria, Santander, Spain

${ }^{b}$ Department of Biosystems Engineering, Ghent University, Gent, Belgium

\section{Rubén Díez-Montero}

Department of Science and Techniques of Water and the Environment.

University of Cantabria, Avda. Los Castros s/n, 39005 Santander, Spain

Phone: +34 942 202286; e-mail: dmonteror@unican.es

\section{Loredana De Florio}

Department of Science and Techniques of Water and the Environment.

University of Cantabria, Avda. Los Castros s/n, 39005 Santander, Spain

Phone: +34 942 202286; e-mail: floriol@unican.es

\section{Marta González-Viar}

Department of Science and Techniques of Water and the Environment.

University of Cantabria, Avda. Los Castros s/n, 39005 Santander, Spain

Phone: +34 942 202286; e-mail: gonzalezvm@unican.es

\section{Eveline I. P. Volcke}

Department of Biosystems Engineering

Ghent University, Coupure links 653, 9000 Gent, Belgium

Phone: +32 926461 29; e-mail: eveline.volcke@ugent.be

\section{Iñaki Tejero (corresponding author)}

Department of Science and Techniques of Water and the Environment.

University of Cantabria, Avda. Los Castros s/n, 39005 Santander, Spain

Phone: +34 942 201802; Fax: +34 942 201703; e-mail: tejeroi@unican.es 


\title{
Feasibility of hydraulic separation in a novel anaerobic-anoxic upflow reactor for biological nutrient removal
}

\author{
This contribution deals with a novel anaerobic-anoxic reactor for biological nutrient \\ removal (BNR) from wastewater, termed AnoxAn. In the AnoxAn reactor, the anaerobic \\ and anoxic zones for phosphate removal and denitrification are integrated in a single \\ continuous upflow sludge blanket reactor, aiming at high compactness and efficiency. Its \\ application is envisaged in those cases where retrofitting of existing wastewater treatment \\ plants for BNR, or the construction of new ones, is limited by the available surface area. \\ The environmental conditions are vertically divided up inside the reactor with the anaerobic \\ zone at the bottom and the anoxic zone above. The capability of the AnoxAn configuration \\ to establish two hydraulically separated zones inside the single reactor was assessed by \\ means of hydraulic characterization experiments and model simulations. Residence time \\ distribution (RTD) experiments in clean water were performed in a bench-scale (48.4 L) \\ AnoxAn prototype. The required hydraulic separation between the anaerobic and anoxic \\ zones, as well as adequate mixing in the individual zones, was obtained through selected \\ mixing devices. The observed behaviour was described by a hydraulic model consisting of \\ continuous stirred tank reactors and plug-flow reactors. The impact of the denitrification \\ process in the anoxic zone on the hydraulic separation was subsequently evaluated through \\ model simulations. The desired hydraulic behaviour proved feasible, involving little mixing \\ between the anaerobic and anoxic zones (mixing flowrate $40.2 \%$ of influent flowrate) and \\ negligible nitrate concentration in the anaerobic zone (less than $0.1 \mathrm{mgN} \mathrm{L}^{-1}$ ) when \\ denitrification was considered.
}

Keywords: wastewater treatment; denitrification; tracer tests; hydrodynamic behaviour; mathematical modelling; numerical simulation

\section{Introduction}

The presence of the nutrient elements nitrogen and phosphorus in wastewater discharged into water bodies is the major cause of eutrophication. Conventional configurations for biological nutrient removal (BNR) require anaerobic and anoxic compartments, besides aerobic ones which are sufficiently large to establish nitrification, which results in a significant volume increase compared to the one needed for organic matter removal only. The larger footprint needed for the retrofitting of existing wastewater treatment plants (WWTP) to achieve BNR is often not available. In the same way, the construction of new WWTPs discharging into sensitive areas may also be limited by the available surface area or may be more conveniently solved by installing compact configurations.

For BNR, separate anoxic and anaerobic conditions are required. In the anaerobic zone, phosphate is released through the phosphate accumulating organisms (PAO) metabolism, which can only take place under strict nitrate absence. In the anoxic zone, nitrate serves as an electron acceptor allowing organic matter consumption for denitrification. The accumulation of phosphate by PAO takes place in excess of 
metabolic requirements, under aerobic conditions. Phosphate uptake is also feasible using nitrate as sole electron acceptor, instead of oxygen [1], which leads to energy savings for aeration, less sludge production and maximal influent organic substrate exploitation [2].

To avoid the construction of separate tanks, anaerobic and anoxic conditions can be established through sequential operation in a single reactor. For instance, the alternation of anoxic and anaerobic conditions through intermittent recirculation of the nitrate-rich flow effluent from the aerobic zone to the anoxic/anaerobic zone was obtained by Ahn et al. and Song et al. at lab-scale [3] and at pilot-scale [4, 5]. However, the separation in time of the anaerobic and anoxic conditions while keeping continuous wastewater inflow may hinder the achievement of both high nitrogen and phosphorus removal efficiencies.

Better efficiencies may be realized through the separation of the anaerobic and anoxic conditions in space. Few studies have been found compacting the anaerobic and anoxic zones in a single suspended sludge reactor. Kwon et al. [6] proposed an upflow multi-layer suspended sludge bioreactor with a plugflow circulation; the reactor was fed with raw wastewater and a nitrate-rich stream recycled from the subsequent aerobic reactor by means of rotating distributors at the bottom. This flow generates an anoxic zone, followed by an upper anaerobic one. However, in such configuration, the availability of biodegradable substrate needed for phosphate release in the anaerobic zone is limited due to consumption during denitrification in the previous anoxic zone. For this reason, configurations with an anaerobic zone preceding an anoxic one are preferred for biological phosphorus removal.

The reactor studied in this contribution was patented and identified by the name AnoxAn [7]. It is a continuous upflow sludge blanket reactor, aimed at achieving high compactness and efficiency. Advantages of upflow bioreactors are energy saving for mixing, plug-flow and sustainable high sludge concentration [8]. The setup, with an anaerobic zone at the bottom prior to an anoxic zone above, avoids the use of chemicals and the need of additional source of organic matter for BNR by means of Enhanced Biological Phosphorus Removal (EBPR) and anoxic pre-denitrification, as it is in the configurations $\mathrm{A}^{2} / \mathrm{O}$, Modified Bardenpho, UCT and VIP [9]. A clarification zone at the top of the reactor avoids the escape of large amounts of biomass, thus promoting simultaneous denitrification and phosphate uptake. Overall, the novel configuration claims anaerobic phosphate release, anoxic denitrification and phosphate uptake in a single reactor.

One of the main goals of the AnoxAn reactor setup is to establish the anoxic-anaerobic hydraulic separation while achieving adequate mixing conditions in the two zones and keeping the continuous influent flow up-way through it. The concept of hydraulic separation in this study is interpreted as the ability of maintaining two zones under different environmental conditions inside the single reactor, including negligible nitrate concentration in the anaerobic zone. The feasibility assessment of the desired hydraulic behaviour, prior to the evaluation of its biological performance treating wastewater, was considered essential and is addressed in this study. For this purpose, residence time distribution (RTD) analysis coupled with hydraulic modelling of a prototype of the AnoxAn reactor was carried out. The RTD of a reactor represents the lapse of time a fluid element spends inside the reactor. This can be obtained by a pulse-input tracer test consisting in the addition of a tracer into the feed stream entering a 
reactor and measuring the outlet concentration of the tracer as a function of time. RTD analysis has been widely used to determine important hydraulic characteristics in wastewater treatment bioreactors such as mixing conditions [10-12], type and characteristics of flow [13-17], dead volume [11, 13, 14, 16], channelling [15, 18, 19] and dispersion [12, 16, 18, 19], contributing in the description of non-ideal flow. The non-ideal hydraulic behaviour of a reactor can be described by several models, among them the tankin-series model and the dispersion model [17]. The former consists in the division of the reactor volume into several continuous stirred tank reactors (CSTR) connected in series, while the latter consists of a plug-flow reactor (PFR) with a diffusive component in the axial direction. These models can be applied to simple flow-through reactors, while more complex flow patterns, such as the AnoxAn reactor containing two hydraulically separated zones, require special consideration and comprehensive characterization [20]. A model based on the combination of ideal CSTR and PFR with axial dispersion, consistently representing the actual reactor, was proposed.

This contribution aims at a better understanding of the AnoxAn reactor hydraulics to assess its feasibility and scalability in treating urban wastewater. First, the reactor was hydraulically characterized by means of experimental tracer tests with clean water. The results of the hydraulic characterization were used to select the mixing devices, to set the internal recycle flowrate, to evaluate the mixing of each zone and to propose a model describing the hydraulic behaviour observed. The model was used to evaluate the extent of hydraulic separation between the anaerobic and anoxic zones, with and without considering biological nitrate consumption (denitrification). Finally, it was also investigated how the presence of biomass inside the reactor contribute to the hydraulic separation between both zones. This study is considered a necessary step for the development of the novel technology, proving the feasibility of the proposed configuration.

\section{Materials and methods}

\section{Reactor setup}

A prototype of the AnoxAn reactor was designed and built up at bench-scale (Figure 1). The $48.4 \mathrm{~L}$ AnoxAn reactor was made of polymethyl methacrylate (PMMA) with an internal square section of $0.20 \mathrm{x}$ $0.20 \mathrm{~m}^{2}$ and a height of $1.30 \mathrm{~m}$. The upflow reactor contains an anaerobic zone at the bottom $(12.4 \mathrm{~L} ; 26$ \%), an anoxic zone above (32.0 L; 66 \%) and a clarification zone at the top (4.0 L; 8 \%). An AnoxAn reactor is typically followed by an aerobic reactor (not displayed in Figure 1), from which a nitrate-rich stream is recycled to the anoxic zone of AnoxAn for denitrification. The suspended biomass in the reactor is exposed to the anaerobic and anoxic conditions needed for EBPR and denitrification. 

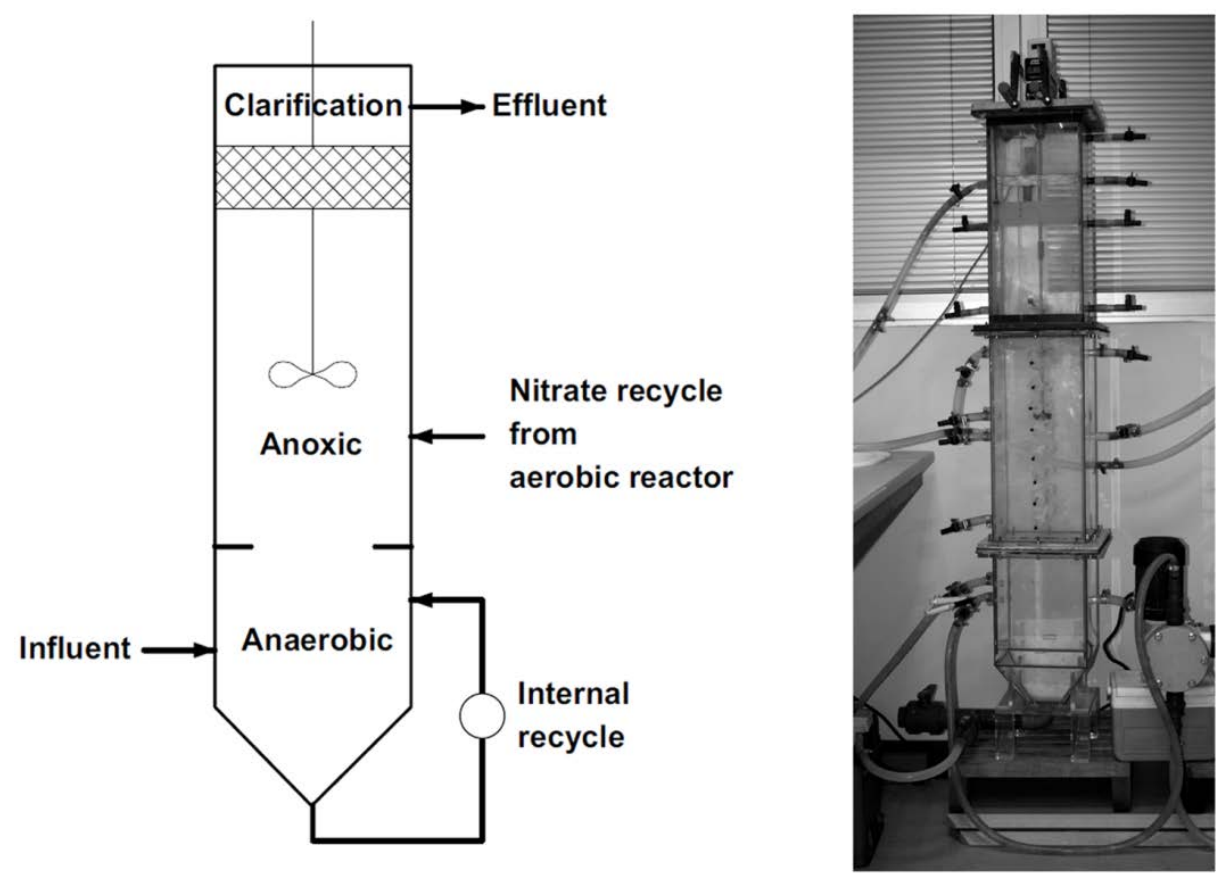

Fig. 1 Schematic diagram (left) and picture (right) of the AnoxAn bench-scale reactor

The selection of the mixing devices for the AnoxAn prototype was performed based on tracer tests in clean water with methylene blue, which were visually analyzed. The desired hydraulic conditions in the reactor were achieved through mechanical mixing. A Heidolph RZR-2000 impeller (100 rpm) was used for the anoxic zone while continuous internal recycle of the anaerobic zone was carried out by means of a peristaltic pump Watson Marlow 313U. The hydrodynamic reactor behaviour was further optimized introducing an expanded polyvinyl chloride (PVC) baffle of $0.040 \mathrm{~m}$ width along the wall, between the anoxic and anaerobic zones, to limit the flow exchange. A baffle of a rigid horizontal polyethylene (PE) net of $0.039 \mathrm{~m}$ height was inserted $0.10 \mathrm{~m}$ below the water surface to establish the upper clarification zone.

The AnoxAn reactor was designed for a Hydraulic Residence Time (HRT) up to 5 h (depending on the organic load applied), corresponding with an influent flowrate $\left(\mathrm{Q}_{\text {in }}\right)$ of approximately $10 \mathrm{~L} \mathrm{~h}^{-1}$. The nitrate recycle rate was set to about 3 times the influent flowrate $\left(\mathrm{R}_{\mathrm{NR}} \approx 3\right)$.

\section{Residence time distribution (RTD) experiments}

A concentrated solution of sodium chloride $\left(\mathrm{NaCl}, 350 \mathrm{~g} \mathrm{~L}^{-1}\right)$ was used as tracer for the RTD tests in clean water. The conductivity of the effluent was measured with a Hach CDC40103 probe, connected to a HQ30d meter. From the conductivity measurement, the corresponding tracer concentration was evaluated through a previously established linear relationship, as in Tang et al. [22] and Martín-Dominguez et al. [23]. Each experiment was preceded by an electrical conductivity measurement of the tap water used during the RTD test. This value was deducted from the electrical conductivity measured at the outlet before calculating the tracer $(\mathrm{NaCl})$ concentration.

The RTD experiments were performed through pulse injection of the tracer into the feed stream entering the reactor and measuring its concentration in the outlet stream as a function of time [21]. Due to the 
complexity of the reactor configuration, including several mixing devices and baffles, separate RTD tests were carried out for the individual anaerobic and anoxic zones and for the overall reactor, as displayed in Figure 2. Table 1 summarizes the experimental conditions. The tests RTD1, RTD2 and RTD3 correspond with the bottom (anaerobic) zone at different internal recycle ratio $\left(\mathrm{R}_{\mathrm{IR}}\right)$ providing different mixing conditions and thus a different turnover rate of the anaerobic volume. The RTD4 test relates to the top zones (anoxic + clarification), injecting the tracer in the nitrate recycle stream. The overall reactor behaviour was studied by the RTD5 test.

An additional tracer test for the overall reactor (Figure 2, setup c) was performed with biomass inside the reactor. This test was carried out after several months of operation treating municipal wastewater, once stable biomass concentrations were achieved, in order to evaluate to which extent the presence of biomass influenced the hydraulic separation between the two zones (anoxic-anaerobic). A solution of lithium chloride ( $\mathrm{LiCl}$ ) was used as tracer, which was continuously injected in the nitrate recycle with a constant concentration of lithium (11.15 mgLi L $\left.{ }^{-1}\right)$. In this way, the effect of a nitrate-rich stream coming from the subsequent aerobic reactor was observed, by comparing the resulting tracer concentrations in the anoxic and anaerobic zones of the reactor. Samples of both the anaerobic and anoxic zones were periodically collected and the concentration of $\mathrm{Li}$ was measured by atomic absorption spectroscopy in a PERKIN ELMER AAnalyst 300 Atomic Absorption Spectrometer.

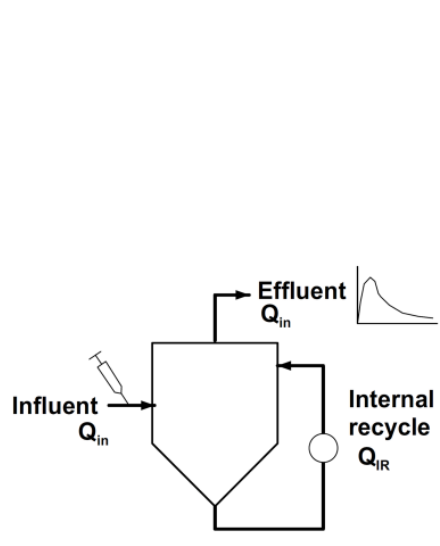

(a)

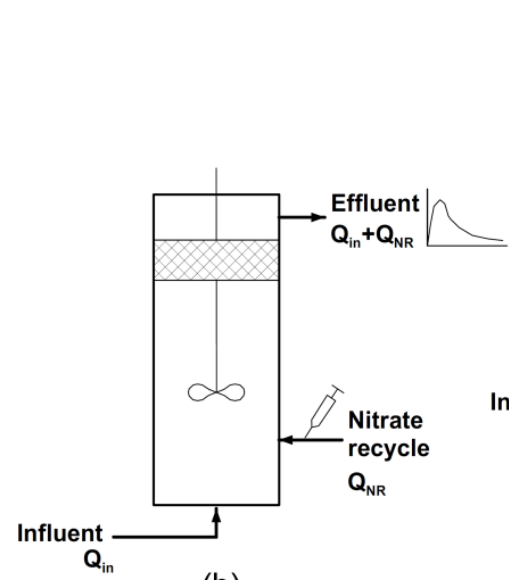

(b)

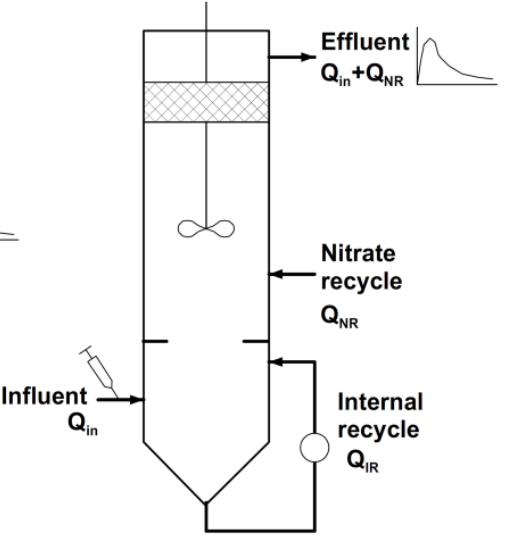

(c)

Fig. 2 Schematic diagram of the three RTD experimental setups: (a) anaerobic zone, (b) anoxic and clarification zones, and (c) overall AnoxAn reactor 
Table 1 Residence time distribution experimental conditions

\begin{tabular}{lccccc}
\hline RTD experiment & $\begin{array}{c}\mathbf{V} \\
(\mathbf{L})\end{array}$ & $\begin{array}{c}\mathbf{Q}_{\text {in }} \\
\left(\mathbf{L} \mathbf{h}^{-1}\right)\end{array}$ & $\begin{array}{c}\mathbf{R}_{\mathrm{IR}} \\
\left(\mathbf{Q}_{\mathrm{IR}} / \mathbf{Q}_{\text {in }}\right)\end{array}$ & $\begin{array}{c}\text { Anaerobic volume } \\
\text { turnover rate } \\
\left(\mathbf{Q}_{\mathrm{IR}} / \mathbf{V}_{\text {anaerobic }} \mathbf{h}^{-1}\right)\end{array}$ & $\begin{array}{c}\mathbf{R}_{\mathrm{NR}} \\
\left(\mathbf{Q}_{\mathrm{NR}} / \mathbf{Q}_{\text {in }}\right)\end{array}$ \\
\hline RTD1 (anaerobic zone) & 12.4 & 10.8 & 3.33 & 2.9 & - \\
\hline RTD2 (anaerobic zone) & 12.4 & 10.8 & 5.56 & 4.8 & - \\
\hline RTD3 (anaerobic zone) & 12.4 & 10.8 & 7.78 & 6.8 & - \\
\hline RTD4 (anoxic and clarification zones) & 36.0 & 10.6 & - & -13 \\
\hline RTD5 (overall reactor) & 48.4 & 10.4 & 5.77 & 4.8 & 2.98 \\
\hline
\end{tabular}

\section{Hydraulic reactor model}

Based on the results of the RTD experiments, a hydraulic model for the reactor was set up and implemented in AQUASIM [24]. Several alternatives to represent the physical compartments and thus mimic hydraulic behaviour of the reactor were tested through trial-and-error. The anaerobic zone was represented as a single CSTR or a series of two or three CSTRs, with different volumes, connections and recycle streams. For the anoxic and clarification zones, several combinations of CSTRs and PFR with axial dispersion were tested. The selected setups for the anaerobic zone on the one hand and the anoxic and clarification zone on the other hand were combined to form the hydraulic model for the overall AnoxAn reactor, while adding an additional interconnection between the anoxic and anaerobic zones. The total volume of these compartments was set equal to the total reactor volume (48.4 L).

The best model was identified based on the calculation of $\chi^{2}$, i.e. the sum of the squares of the weighed deviations between measurements and simulation results, as follows:

$$
\chi^{2}(\mathrm{p})=\sum_{\mathrm{i}=1}^{\mathrm{n}}\left(\frac{\mathrm{y}_{\mathrm{i}}(\mathrm{p})-\mathrm{y}_{\text {meas }, \mathrm{i}}}{\sigma_{\text {meas }}}\right)^{2}
$$

Where:

$$
\begin{aligned}
& y_{\text {meas }, i}=\text { measured tracer concentration at time i } \\
& \sigma_{\text {meas }}=\text { global standard deviation of the measured tracer concentration } \\
& y_{i}(p)=\text { the } \mathrm{i}^{\text {th }} \text { simulated value at time } \mathrm{i} \\
& p=\left(p_{1}, \ldots, p_{m}\right)=\text { the model parameters } \\
& n=\text { the number of data points }
\end{aligned}
$$

Furthermore, the coefficient of determination $\mathrm{R}^{2}$ was calculated for each model, as follows:

$$
R^{2}=1-\frac{S S_{\text {err }}}{S S_{\text {tot }}}
$$




$$
\begin{gathered}
S S_{\text {err }}=\sum_{i=1}^{n}\left(y_{i}-y_{\text {meas }, i}\right)^{2} \\
S S_{\text {tot }}=\sum_{i=1}^{n}\left(\overline{y_{\text {meas }}}-y_{\text {meas }, i}\right)^{2}
\end{gathered}
$$

Where:

$$
\begin{aligned}
& S S_{\text {err }}=\text { residual sum of squares } \\
& S S_{\text {tot }}=\text { total sum of squares (proportional to the sample variance) } \\
& \overline{y_{\text {meas }}}=\text { average value of measured tracer concentration }
\end{aligned}
$$

The optimum values for the parameters p, being the input tracer concentration, the diffusion coefficient in the axial dispersion model and the interconnection flowrate between the anoxic and anaerobic zones, were obtained by fitting the model results to the experimental RTD data. The best models were selected as constituting a compromise between model complexity (number of compartments) and data fit (low $\chi^{2}$ ).

Finally, the obtained model was used to evaluate the hydraulic separation between the two zones of the reactor (anoxic-anaerobic). Similarly to the experimental tracer test performed with biomass inside the reactor, the continuous injection of a tracer component in the nitrate recycle was simulated to study the effect of a nitrate-rich stream coming from the subsequent aerobic reactor, by comparing the resulting steady tracer concentrations throughout the reactor. The extent of the separation was evaluated not taking into consideration the biological activity, i.e. only due to hydraulic separation. Subsequently, a saturation type (Monod equation) [9] denitrification model was included in the anoxic zone in order to assess the influence of the nitrate consumption:

$$
\frac{\mathrm{dC}_{\mathrm{NO} 3}}{\mathrm{dt}}=-\mathrm{k} \cdot \frac{\mathrm{C}_{\mathrm{NO} 3}}{\mathrm{~K}_{\mathrm{NO} 3}+\mathrm{C}_{\mathrm{NO} 3}} \cdot \mathrm{X}_{\mathrm{H}}=-\frac{1-\mathrm{Y}_{\mathrm{H}}}{2.86 \cdot \mathrm{Y}_{\mathrm{H}}} \cdot \mu_{\mathrm{H}} \cdot \eta_{\mathrm{NO} 3} \cdot \frac{\mathrm{C}_{\mathrm{NO} 3}}{\mathrm{~K}_{\mathrm{NO} 3}+\mathrm{C}_{\mathrm{NO} 3}} \cdot \mathrm{X}_{\mathrm{H}}
$$

Where:

$$
\begin{aligned}
& C_{\mathrm{NO} 3}=\text { nitrate concentration }\left(\mathrm{mgN} \mathrm{L}^{-1}\right) \\
& k=\text { denitrification rate }\left(\mathrm{mgN} \mathrm{gVSS}^{-1} \mathrm{day}^{-1}\right) \\
& K_{\mathrm{NO} 3}=\text { half saturation constant for nitrate }\left(\mathrm{mgN} \mathrm{L}^{-1}\right) \\
& X_{H}=\text { heterotrophic biomass concentration }\left(\mathrm{mgVSS} \mathrm{L}^{-1}\right) \\
& Y_{H}=\text { heterotrophic yield coefficient (dimensionless) } \\
& \mu_{H}=\text { maximum growth rate on substrate }\left(\text { day }^{-1}\right) \\
& \eta_{H}=\text { reduction factor for denitrification (dimensionless) }
\end{aligned}
$$

The denitrification kinetics (Eq. (5)) were adapted from the Activated Sludge Model ASM2d [25], assuming substrate, nutrients, and alkalinity to be present in non-limiting amounts, in the absence of dissolved oxygen. Typical values for the kinetic $\left(K_{N O 3}, \mu_{H}, \eta_{H}\right)$ and stoichiometric $\left(Y_{H}\right)$ parameters were used as proposed in the ASM2d [25]. 


\section{Results and discussion}

\section{Residence time distribution tests}

The residence time distribution profiles for the three experiments performed in the anaerobic zone at different internal recycle rates (RTD1, RTD2 and RTD3) are illustrated in Figure 3. The goal of these tests was to identify the lowest internal recycle rate which still guarantees good mixing. RTD1 shows a significant delay in the peak, which is attributed to slow mixing. Both RTD2 and RTD3 give rise to a sharp peak, which is similar to the hydraulic behaviour of a CSTR. Between the latter options, an internal recycle ratio of 5.56, as performed in RTD2 experiment, was chosen since it involves the least energy consumption. This internal recycle ratio corresponds with a turnover rate of the reactor of 4.8 times per hour, which is higher than the practical design value of 3 times per hour [26]. This rate should be high enough to accomplish sufficient mixing and low enough to prevent unwanted oxygen transfer from the atmosphere due to excessive turbulence. However, in the AnoxAn reactor configuration, the latter is prevented by its own design, as the anaerobic zone is not exposed to the atmosphere.

The delay of approximately 4 minutes in the sharp peak of RTD2 compared to the theoretical CSTR profile can be explained by the fact that the internal recycle is pumped from the bottom to the top of the anaerobic zone, producing a countercurrent downflow and in this way slightly delaying the arrival of the tracer in the outlet.

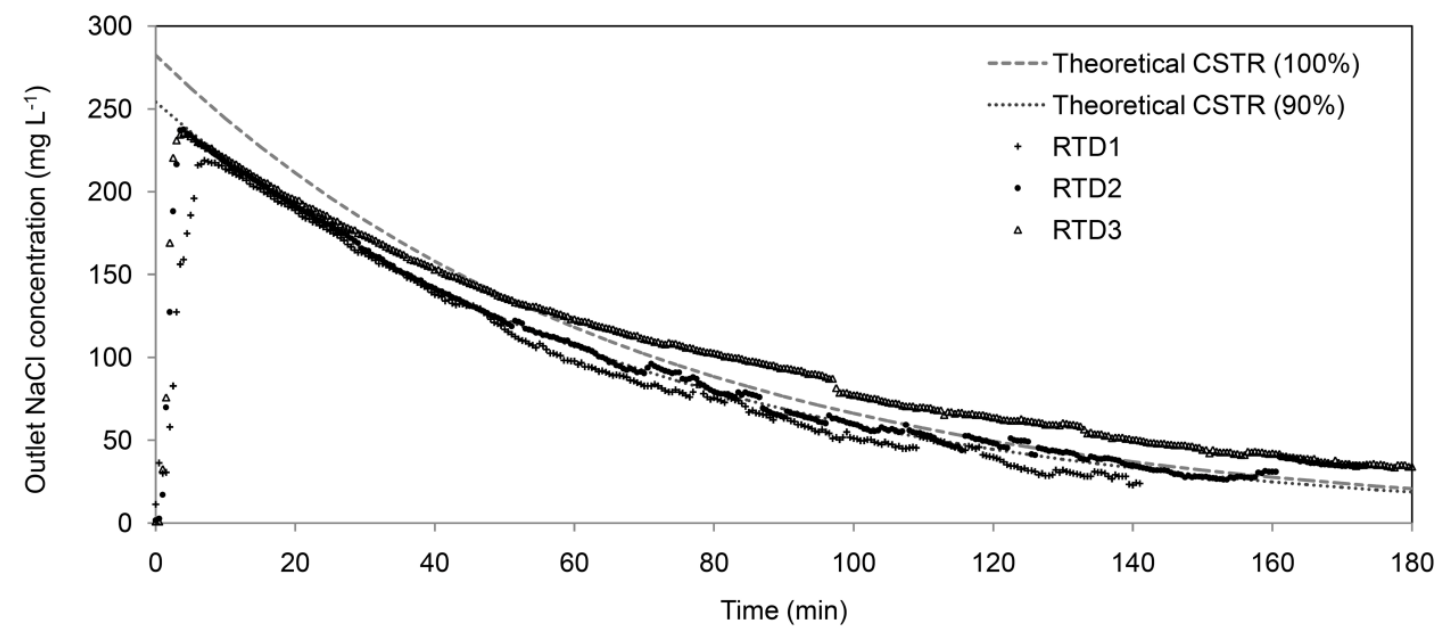

Fig. 3 Residence time distribution profiles for anaerobic zone experiments RTD1 ( $\mathrm{R}_{\mathrm{IR}}=3.33$ ), RTD2 $\left(\mathrm{R}_{\mathrm{IR}}=5.56\right)$, RTD3 $\left(\mathrm{R}_{\mathrm{IR}}=7.78\right)$ and theoretical CSTR with $100 \%$ and $90 \%$ tracer recovery

To characterize the flux in the anoxic zone and the influence of the clarification zone, a tracer pulse was injected in the nitrate recycle flow (with rate $\mathrm{Q}_{\mathrm{NR}}$ ). The resulting outlet tracer concentration profile (RTD4 in Figure 4(b)) shows a sharp peak followed by a long tail, similar to the behaviour of a CSTR, but with shift forward of approximately 18 minutes, possibly caused by the influence of the upper clarification zone. The baffle inserted between the anoxic and clarification zones impedes an immediate and complete mixing of the upper part of the reactor. The delay in the rise of the RTD profile can be attributed to non-ideal plug-flow behaviour in the volume under the influence of the baffle and the clarification zone, which can be described by means of an axial dispersion model consisting of an ideal 
PFR with a diffusive component in the axial direction. The remaining volume of the reactor, which represents the anoxic zone, is assumed to be completely mixed by the impeller.

The global RTD profile for the overall AnoxAn reactor is displayed in Figure 4(c) (RTD5). The outlet tracer concentration trend shows a complex non-ideal flux type, which should be represented by the combination of the setups proposed for the individual anaerobic and anoxic plus clarification zones. The tail of the RTD shows a slight cyclical pattern, which may be due to the presence of an internal recycle as explained in Levenspiel [21]. However, since the amplitude of these oscillations is relatively small, they were neglected in order not to increase the model complexity.

The amount of tracer recovered in the individual experiments was calculated and related to the theoretical amount of tracer injected. A tracer recovery of $81.8 \%, 79.7 \%$ and $75.4 \%$ was obtained for the experiments RTD2, RTD4 and RTD5, respectively. The incomplete tracer recovery could be attributed to inaccuracies during the tracer solution preparation and manipulation (syringe injection). 

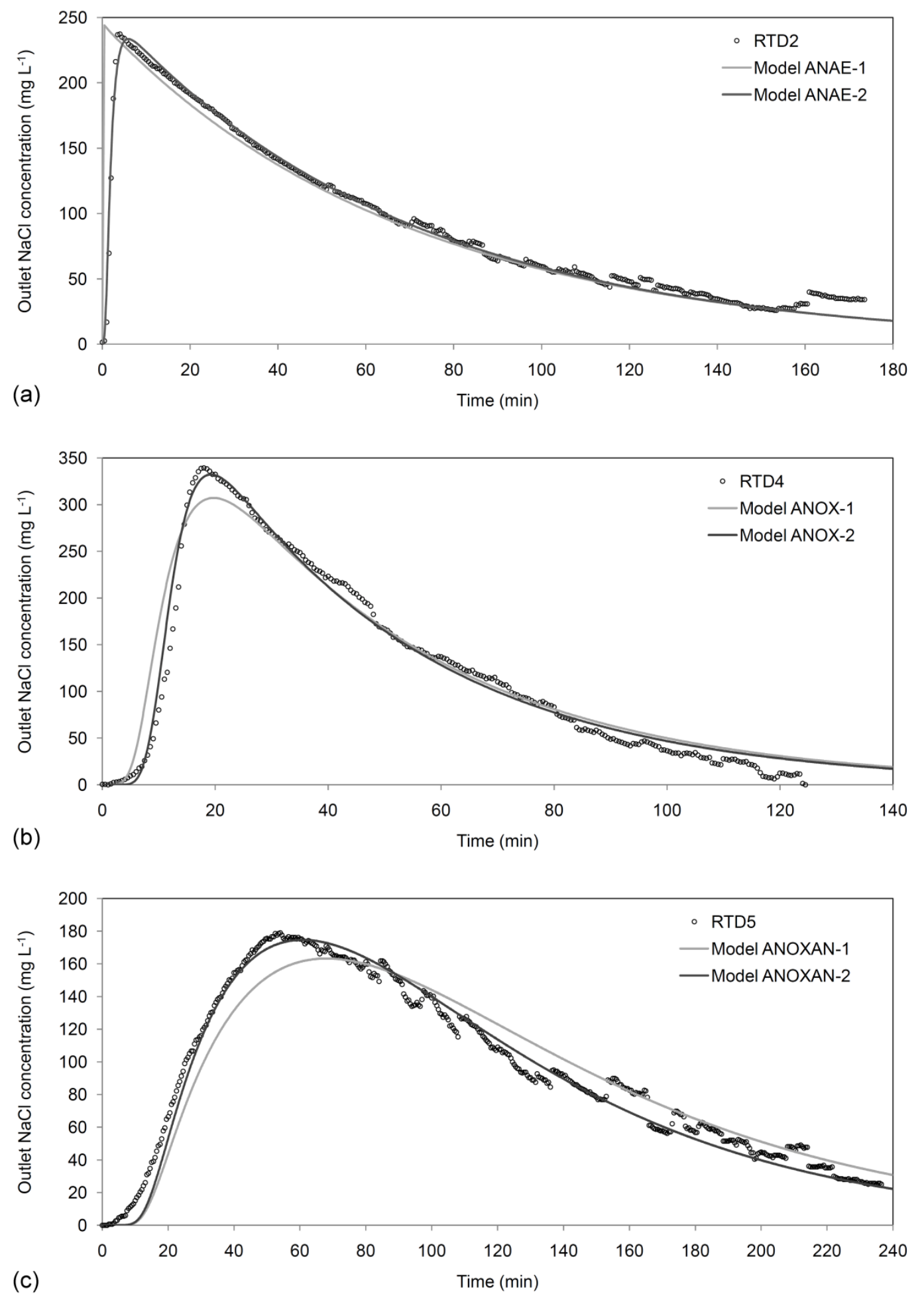

Fig. 4 Comparison of experimental (white circles) and simulated (full lines) RTD for the three experimental setups: (a) anaerobic zone, (b) anoxic and clarification zones, and (c) overall AnoxAn reactor. Simulations -1 and -2 refer to two different model setups presented in the next section 


\section{Hydraulic reactor model}

Anaerobic zone

Several alternatives were implemented to represent the anaerobic zone in the hydraulic model. Two of them are presented together with the experimental RTD2 in Figure 4(a). Model setup ANAE-1 consists of a single mixed reactor compartment. The second setup ANAE-2 is represented in Figure 5(a) and consists of a combination of 3 mixed reactor compartments in series, representing the main anaerobic zone (compartment 1, 10.6 L), the hopper at the bottom of the reactor (compartment 2, $1.4 \mathrm{~L}$ ) and the upper layer receiving the internal recycle (compartment 3, $0.4 \mathrm{~L}$ ). The second setup allows simulating the effect of the internal recycle pumped from the bottom compartment to the top compartment, on its turn providing a downflow in the anaerobic zone. The latter was represented through a bifurcation from the outlet of the top compartment (3) to the main compartment (1). Its flowrate $\mathrm{Q}_{31}$ was defined as a fraction of the influent flowrate $Q_{\text {in }}$ :

$$
Q_{31}=Q_{I R}-Q_{i n}=\left(\frac{Q_{I R}}{Q_{i n}}-1\right) \cdot Q_{i n}=\left(R_{I R}-1\right) \cdot Q_{i n}=f_{1} \cdot Q_{i n}
$$

The parameter $f_{1}$ was calculated as $\mathrm{R}_{\mathrm{IR}}-1=4.56$ to represent the actual internal recycle flow.

The fit between the model simulation and the experimental results was significantly improved with the 3 compartments model (ANAE-2) compared to the single mixed reactor compartment (ANAE-1), as it is clear from Figure 4(a) and from the $\chi^{2}$ values shown in Table 2, achieving a coefficient of determination $\mathrm{R}^{2}$ of 0.99 .

A parameter estimation was carried out in order to estimate the amount of tracer input. The results are displayed in Table 2. The tracer recovery estimated from the ANAE-2 model fit was somewhat higher than the amount of tracer recovered experimentally (87.1\% versus $81.8 \%$ ), which may be due to the limited duration of the experimental measurements. It also suggested that the reduced experimental tracer recovery may be due to overestimation of the actual amount of tracer injected during the tests. 


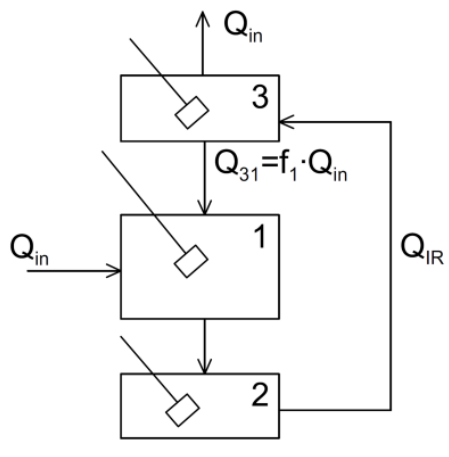

(a)

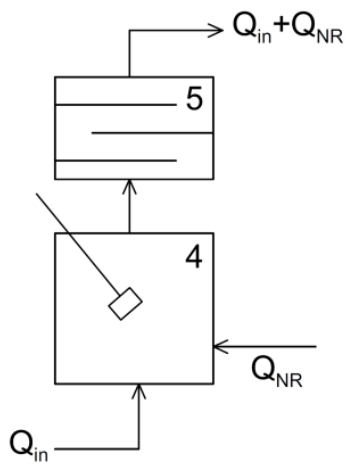

(b)

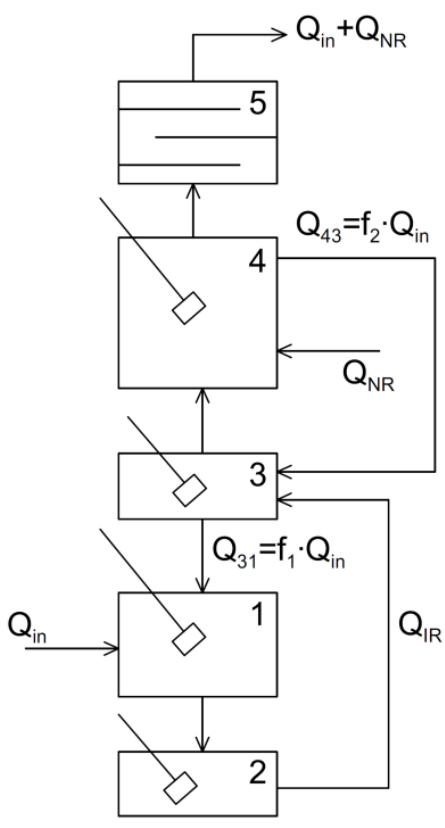

(c)

Fig. 5 Schematic diagram of the final hydraulic models: (a) anaerobic zone ANAE-2, (b) anoxic and clarification zones ANOX-1/ANOX-2 and (c) overall AnoxAn reactor ANOXAN-1/ANOXAN-2

Table 2 Hydraulic model parameters and resultant $\chi^{2}$ and $\mathrm{R}^{2}$

\begin{tabular}{|c|c|c|c|c|c|c|}
\hline Setup & $\mathbf{f}_{1}$ & $\mathbf{f}_{2}$ & $\begin{array}{c}D \\
\left(m^{2} s^{-1}\right)\end{array}$ & $\begin{array}{c}\text { Tracer input } \\
\text { (\%) }\end{array}$ & $\chi^{2}$ & $\mathbf{R}^{2}$ \\
\hline ANAE-1 & - & - & - & $86.2^{\mathrm{a}}$ & 33.7 & 0.95 \\
\hline ANAE-2 & 4.56 & - & - & $87.1^{\mathrm{a}}$ & 3.7 & 0.99 \\
\hline ANOX-1 & - & - & $8.9 \cdot 10^{-6}$ a & $89.4^{\mathrm{a}}$ & 12.4 & 0.95 \\
\hline ANOX-2 & - & - & $3.6 \cdot 10^{-6}$ a & $86.8^{\mathrm{a}}$ & 3.9 & 0.99 \\
\hline ANOXAN-1 & 4.77 & 0 & $3.6 \cdot 10^{-6}$ & $83.6^{\mathrm{a}}$ & 31.6 & 0.93 \\
\hline ANOXAN-2 & 4.77 & $0.402^{\mathrm{a}}$ & $3.6 \cdot 10^{-6}$ & $78.8^{\mathrm{a}}$ & 10.8 & 0.98 \\
\hline
\end{tabular}

${ }^{a}$ Obtained by parameter estimation

\section{Anoxic and clarification zones}

Among several alternative hydraulic models to represent the anoxic and clarification zones, a configuration consisting of a mixed reactor followed by an advective-diffusive compartment was selected. Different values were tested for the volumes of these reactors (compartments 4 and 5 in Figure 5(b)) which were set at $30 \mathrm{~L}$ and $6 \mathrm{~L}$ for ANOX-1 and at $28.8 \mathrm{~L}$ and $7.2 \mathrm{~L}$ for ANOX-2 (corresponding to the same total volume). ANOX-1 represents the clarification zone and the volume occupied by the baffle by means of a PFR with axial dispersion, while ANOX-2 considers non-ideal PFR for the clarification zone 
and the baffle plus 1.2 L volume under the baffle influence.

A parameter estimation was carried out in order to determine the diffusion coefficient $\mathrm{D}$ of the non-ideal PFR and the amount of tracer (Table 2). The diffusion coefficient D was estimated at $8.9 \cdot 10^{-6} \mathrm{~m}^{2} \mathrm{~s}^{-1}$ and $3.6 \cdot 10^{-6} \mathrm{~m}^{2} \mathrm{~s}^{-1}$ for setup ANOX-1 and ANOX-2, respectively. The corresponding Peclet number (Pe):

$$
P e=\frac{U \cdot L}{D}
$$

in which $U$ is the upflow velocity $\left(\mathrm{m} \mathrm{s}^{-1}\right.$ ) and $L$ is the length of the compartment $(\mathrm{m})$, is a characteristic for the axial dispersion. A large Pe number indicates low back-mixing (recall that an ideal PFR corresponds with $\mathrm{Pe}=\infty$, while $\mathrm{Pe}=0$ for a CSTR). It was calculated as 5.1 and 15.2, for ANOX-1 and ANOX-2 respectively. Taking $\mathrm{Pe} \leq 5$ as the criterion of greater back-mixing (CSTR) and $\mathrm{Pe} \geq 50$ as small back-mixing (PFR) [14, 16, 21], both alternatives tended to intermediate between PFR and CSTR. It is clear from Figure 4(b) that the fit between the simulations and the experimental data is better for the second volume distribution option (ANOX-2), achieving a high value for the coefficient of determination, $\mathrm{R}^{2}$, of 0.99 (Table 2). A relatively longer PFR compartment with a lower diffusion coefficient seems to better represent the upper calm zone of the reactor.

The estimated amount of tracer for setup ANOX-2 was somewhat higher than the one recovered experimentally (86.8\% versus $79.7 \%$ ), similarly to the previous anaerobic zone simulations.

\section{Overall AnoxAn reactor}

The model setups ANAE-2 and ANOX-2 were combined (ANOXAN-1) and compared to a configuration with additional mixing between the anoxic and anaerobic zones (ANOXAN-2, Figure 5(c)). For the latter purpose, a bifurcation was included from the anoxic zone (compartment 4) to the anaerobic upper layer (compartment 3). A parameter $\mathrm{f}_{2}$, termed mixing coefficient, was used to define the flowrate $\mathrm{Q}_{43}$ diverted from compartment 4 to compartment 3:

$$
Q_{43}=f_{2} \cdot Q_{\text {in }}
$$

This approach is similar to the one of Heertjes and Van der Meer [27], who proposed a model for upflow anaerobic sludge blanket reactors including return flow or back-mixing between stirred compartments.

The diffusion coefficient $\mathrm{D}$ was set to the value determined previously, during the evaluation of the anoxic and clarification zones, and $\mathrm{f}_{1}$ was set to 4.77 (equal to $\mathrm{R}_{\mathrm{IR}}-1$ ) to represent the actual internal recycle during the experiment RTD5. A parameter estimation was carried out in order to determine the amount of tracer and the mixing coefficient $\mathrm{f}_{2}$ (Table 2). The fit was clearly improved considering the mixing between both zones (ANOXAN-2, Figure 4(c)) achieving a coefficient of determination $\mathrm{R}^{2}$ of 0.98. The estimated amount of tracer was again slightly higher than the one recovered experimentally (78.8\% versus 75.4\%). The mixing coefficient $\mathrm{f}_{2}$ was estimated at 0.402 (mixing flowrate $40.2 \%$ of $\mathrm{Q}_{\text {in }}$ ), which is lower than typical anoxic recycle ratio (from the anoxic to the anaerobic reactor) in several conventional BNR configurations, such as UCT [9]. This indicates no excessive mixing takes place, which is desired in the AnoxAn reactor to avoid the loss of the anaerobic condition, since nitrate presence in the theoretically anaerobic zone will prevent EBPR. 
The ultimate model, ANOXAN-2, is considered a reliable hydraulic model for the AnoxAn prototype tested in this study, making it possible to evaluate the feasibility of the novel configuration prior to scaling up and studying the biological performance of the reactor.

To evaluate the hydraulic separation between the two zones of the ANOXAN-2 configuration, a continuous injection of a constant concentration of tracer $\left(5,10,15\right.$ and $\left.20 \mathrm{mg} \mathrm{L}^{-1}\right)$ in the nitrate recycle was simulated. This tracer injection represents a nitrate-rich stream recycled from an ideal subsequent aerobic nitrifying reactor, corresponding to influent wastewater ammonium concentration approximately in the range of 20-80 $\mathrm{mgN} \mathrm{L}^{-1}$. The simulations were performed with the same experimental conditions of the RTD test for the overall reactor, that are $\mathrm{Q}_{\mathrm{in}}=10.4 \mathrm{~L} \mathrm{~h}^{-1}, \mathrm{R}_{\mathrm{IR}}=5.77$ and $\mathrm{R}_{\mathrm{NR}}=2.98$. Figure 6(a) displays the obtained steady state tracer (nitrate) concentrations in the five reactor compartments. The tracer (nitrate) concentration in the anoxic zone (compartment 4) was observed to be 4.3 times higher than the concentration in the anaerobic zone (compartment 1), only due to hydraulic separation. No significant hydraulic separation was observed between the anoxic and clarification zones (compartments 4 and 5) on the one hand and the bottom, middle and top compartments of the anaerobic zone (compartments 1, 2 and 3) on the other hand.

While the nitrate concentration in the anaerobic zone may still be too high for EBPR, it was drastically reduced when denitrification in the anoxic zone was taken into account in the presence of biomass, even with a continuous nitrate injection of $20 \mathrm{mgN} \mathrm{L}^{-1}$ in the recycle stream, as can be observed from Figure 6(b). Nitrate consumption due to biological activity led to reduced nitrate concentration in the anoxic zone, while the ratio between nitrate concentrations in the anoxic and anaerobic zones was the same (about 4.3), indicating that denitrification did not affect the extent of hydraulic separation. However, it is clear from Figure 6(b) that it is required a minimum concentration of biomass $\left(1.2 \mathrm{~g} \mathrm{~L}^{-1}\right)$, which is considered achievable, to maintain negligible concentration of nitrate in the anaerobic zone (less than 0.1 mgN $\mathrm{L}^{-1}$ ), making possible the existence of an actually anaerobic zone below the anoxic one. The denitrification model was only incorporated in the anoxic zone (not in the anaerobic one) in order to assess the required nitrate disappearance in the anaerobic zone, not being influenced by biological activity in such a zone. 

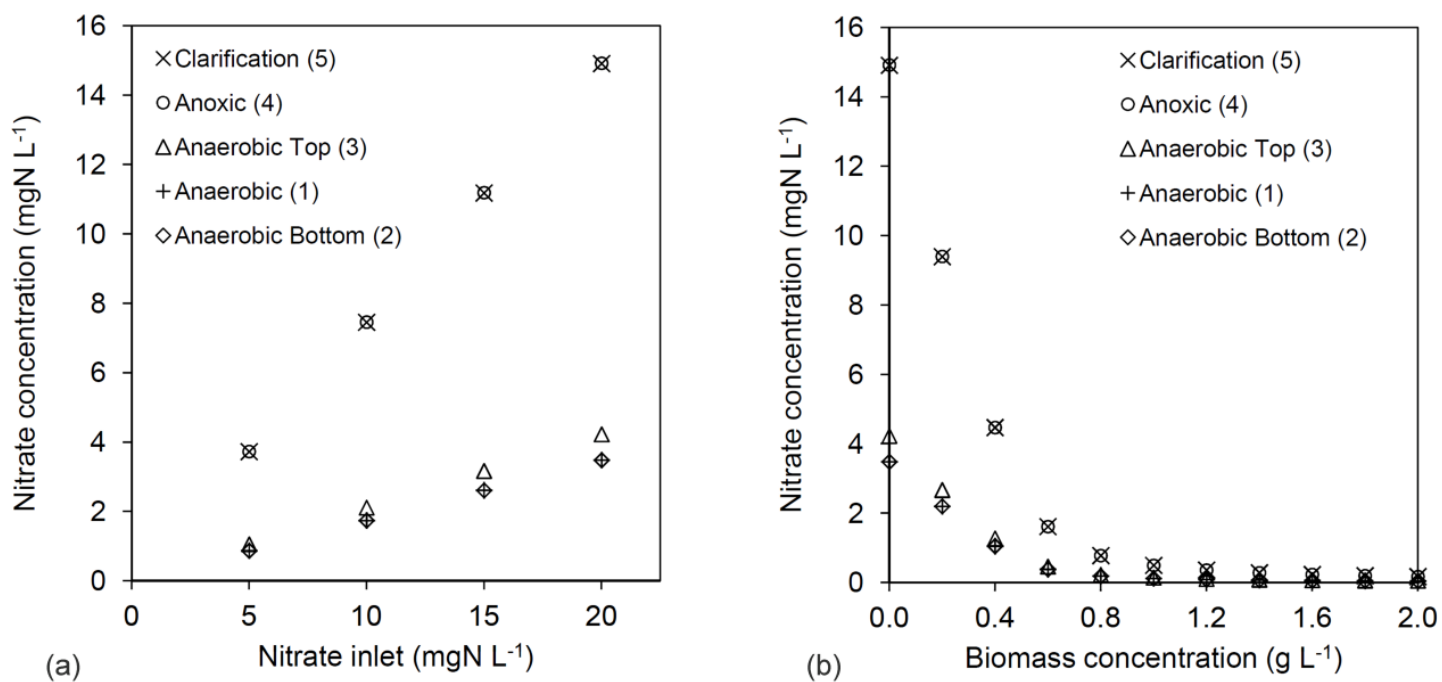

Fig. 6 Tracer (nitrate) concentration in the five model compartments: (a) for different tracer (nitrate) injections in the nitrate recycle inlet not taking into account denitrification and (b) including denitrification model in the anoxic zone with a tracer (nitrate) injection in the nitrate recycle inlet of 20

$$
\mathrm{mgN} \mathrm{L}^{-1}
$$

The subsequent tracer test with biomass, carried out after several months of reactor operation, once the concentration of total suspended solids (TSS) amounted to approximately $5 \mathrm{~g} \mathrm{~L}^{-1}$ in the anoxic zone and $10 \mathrm{~g} \mathrm{~L}^{-1}$ in the anaerobic one, allowed to assess the influence of biomass on the reactor hydrodynamics. The comparison between the tracer $(\mathrm{Li})$ concentrations in the anoxic and anaerobic zones, resulting from the continuous injection of the tracer $(\mathrm{Li})$ in the nitrate recycle, and the simulation results obtained for identical operational conditions without biomass, are shown in Figure 7. It shows that the hydraulic separation is somehow benefitted from the presence of biomass.

In particular, the experimental and simulated lithium concentration profiles in the anoxic zone matched very well. For the anaerobic zone, the measured concentrations were slightly overpredicted through simulation, which suggests that the presence of biomass further increase the hydraulic separation between the anoxic and anaerobic zones. It is attributed to the different TSS concentration in both zones. The lower TSS concentration in the anoxic zone can be imputed mainly to the nitrate recycle stream, which enters the AnoxAn reactor with high flowrate and lower concentration of TSS, thus provoking TSS dilution in the anoxic zone. Due to these different concentrations, different densities in each zone have slightly enhanced the hydraulic separation.

When compared to similar studies, the influence of biomass on the hydrodynamics of bioreactors was shown to have a notable effect for reactors with high biomass concentration and without mechanical mixing, as it is the case for upflow anaerobic sludge blanket reactor, UASB [28; 29]. In these reactor types, the produced biogas bubbles disturb the sludge blanket and lead to mixing, thus affecting the hydrodynamics of the reactor. In the AnoxAn reactor however, the envisaged biomass concentration is higher than the typical value of $3 \mathrm{~g} \mathrm{~L}^{-1}$ in conventional activated sludge processes [9], but still relatively low compared to sludge concentration in UASB reactors, which could exceed $80 \mathrm{~g} \mathrm{~L}^{-1}$ [27]. And what is more, mechanical devices continuously mix each zone avoiding the compacting of the sludge mass and 
limiting the influence of gas bubbles, thus explaining the minor influence of biomass in the AnoxAn reactor hydrodynamics compared to other sludge blanket reactors such as UASB.

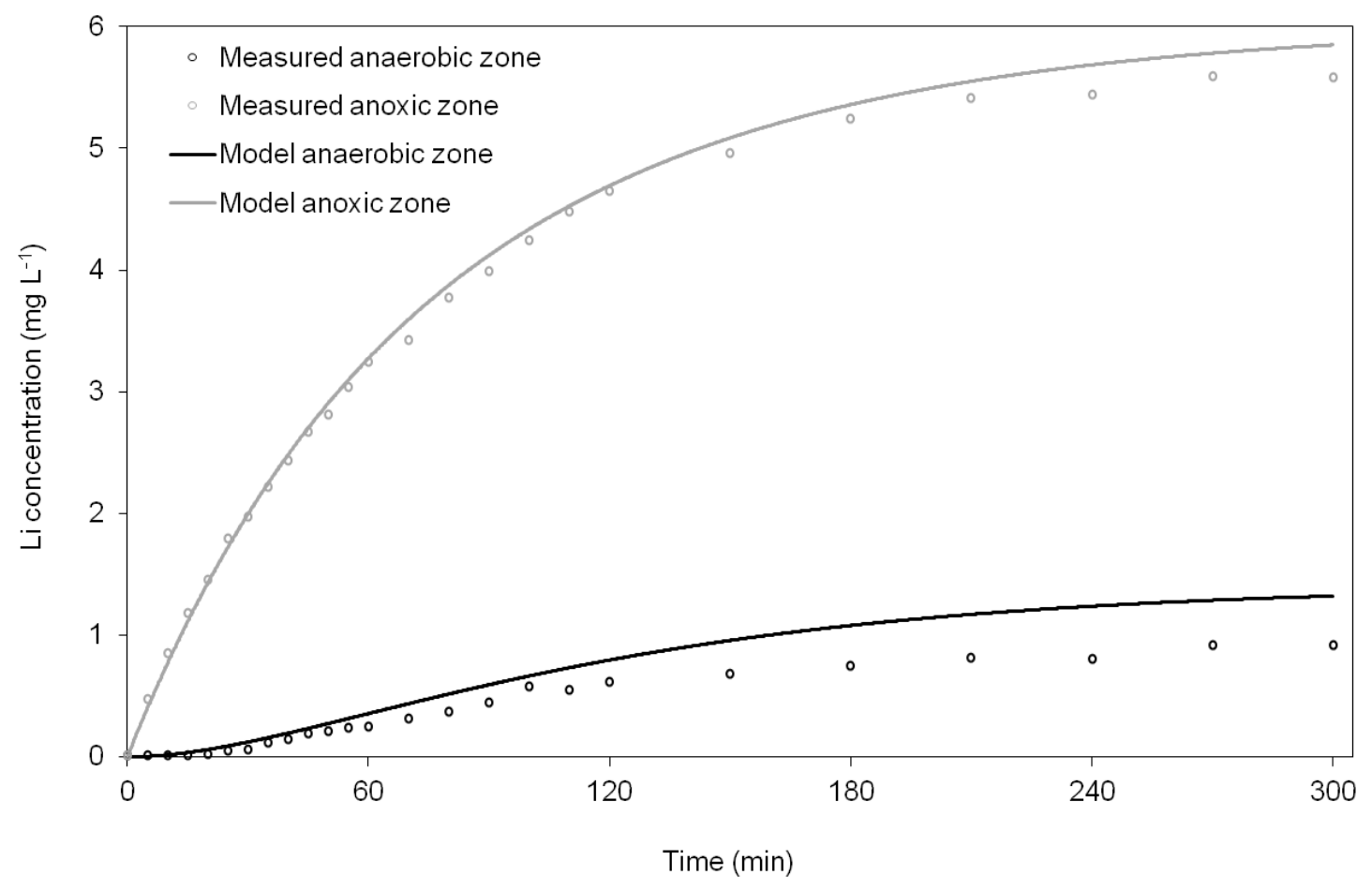

Fig. 7 Tracer (lithium) concentration in the anoxic and anaerobic zones with tracer (lithium) injection in the nitrate recycle inlet of $11.15 \mathrm{mgLi} \mathrm{L}^{-1}$. Comparison between experimental data (with biomass) and simulation results (without biomass)

\section{Conclusions}

A novel anaerobic-anoxic upflow reactor, AnoxAn, is presented as an innovative technology for BNR. The required environmental conditions to achieve EBPR and denitrification imply hydraulic separation between the anaerobic and anoxic zones inside the reactor. Such specific hydraulic behaviour inside the reactor has been tested experimentally at bench-scale and through numerical simulation in order to assess the feasibility of the novel reactor configuration, leading to the following main conclusions:

- The hydraulic behaviour of an AnoxAn prototype has been characterized by means of RTD analysis of the individual anaerobic and anoxic zones, as well as of the overall reactor. Adequate mixing was achieved for each zone.

- A hydraulic model describing the zoning of the reactor has been built up and fitted to the RTD test results. The ultimate setup consists of a combination of four CSTR compartments and one PFR with axial dispersion compartment and will form the basis for the inclusion of biological conversion processes in future.

- The simulation results showed that the desired hydraulic behaviour was achieved, involving little mixing between the anoxic and the anaerobic zones of the AnoxAn reactor. The mixing flowrate between both zones was estimated to be only $40.2 \%$ of influent flowrate. 
- When denitrification in the anoxic zone was taken into account, the ratio between nitrate concentrations in the two zones remained the same and, more important, it resulted in negligible nitrate concentration (less than $0.1 \mathrm{mgN} \mathrm{L}^{-1}$ ) in the anaerobic zone (as desired) for biomass concentrations of $1.2 \mathrm{~g} \mathrm{~L}^{-1}$ or higher. The established hydraulic separation makes the AnoxAn concept ready for further research addressing the performance of the reactor in the removal of organic matter and nutrients from wastewater.

\section{Acknowledgements}

The Spanish Ministries of Education and Science and of Economy and Competitiveness funded our research activity through the projects NOVEDAR (CSD2007-00055), HIBREDAR (CTM2008-06877C02-01_TECNO) and $\mathrm{PBi}^{2}$ (CTM2012-36227), the latter being co-financed by the European Regional Development Fund. The authors also thank Amaya Lobo and Claudio Gómez for their helpful comments and suggestions.

\section{References}

1. Vlekke GJFM, Comeau Y, and Oldham WK (1988) Biological phosphate removal from wastewater with oxygen or nitrate in sequencing batch reactors. Environ Technol Lett 9:791-796

2. Kuba T, Smolders G, van Loosdrecht MCM, and Heijnen JJ (1993) Biological phosphorus removal from wastewater by anaerobic-anoxic sequencing batch reactor. Water Sci Technol 27(5/6):241-252

3. Ahn KH, Song KG, Cho E, Cho J, Yun H, Lee S, and Kim J (2003) Enhanced biological phosphorus and nitrogen removal using a sequencing anoxic/anaerobic membrane bioreactor (SAM) process. Desalination 157(1-3):345-352

4. Song KG, Cho J, Cho KW, Kim SD, and Ahn KH (2010) Characteristics of simultaneous nitrogen and phosphorus removal in a pilot-scale sequencing anoxic/anaerobic membrane bioreactor at various conditions. Desalination 250(2):801-804

5. Song KG, Cho J, and Ahn KH (2009) Effects of internal recycling time mode and hydraulic retention time on biological nitrogen and phosphorus removal in a sequencing anoxic/anaerobic membrane bioreactor process. Bioprocess Biosyst Eng 32:135-142

6. Kwon JC, Park HS, An JY, Shim KB, Kim YH, and Shin HS (2005) Biological nutrient removal in simple dual sludge system with an UMBR (upflow multi-layer bio reactor) and aerobic biofilm reactor. Water Sci Technol 52(10-11):443-451

7. Tejero I, Díez R, Esteban AL, Lobo A, Temprano J, and Rodríguez L (2010) Reactor biológico anóxicoanaerobio para la eliminación de nutrientes de aguas residuales (Anoxic-anaerobic biological reactor for nutrient removal from wastewater). Spanish Patent ES2338979 (in Spanish)

8. Lettinga G, van Velsen AFM, Hobma SW, de Zeeuw WJ, and Klapwijk A (1980) Use of the Upflow Sludge Blanket (USB) reactor concept for biological wastewater treatment. Biotechnol Bioeng 22:699-734

9. Tchobanoglous G, Burton FL, and Stensel HD (2003) Wastewater Engineering: Treatment and Reuse, 4th edn. Metcalf \& Eddy, McGraw-Hill, New York

10. Olivet D, Valls J, Gordillo MA, Freixó A, and Sánchez A (2005) Application of residence time distribution technique to the study of the hydrodynamic behaviour of a full-scale wastewater treatment plant plug-flow bioreactor. J Chem Technol Biotechnol 80:425-432 
11. Hu B, Wheatley A, Ishtchenko V, and Huddersman K (2012) Performance linked to residence time distribution by a novel wool-based bioreactor for tertiary sewage treatment. Appl Microbiol Biot 94:817828

12. Yerushalmi L, Alimahmoodi M, Behzadian F, and Mulligan CN (2013) Mixing characteristics and liquid circulation in a new multi-environment bioreactor. Bioprocess Biosyst Eng 36:1339-1352

13. Fall C, and Loaiza-Navía JL (2007) Design of a tracer test experience and dynamic calibration of the hydraulic model for a full-scale wastewater treatment plant by use of Aquasim. Water Environ Res 79(8):893-900

14. Sarathai Y, Koottatep T, and Morel A (2010) Hydraulic characteristics of an anaerobic baffled reactor as onsite wastewater treatment system. J Environ Sci 22(9):1319-1326

15. Gómez C (2010) Desarrollo y modelización de un sistema biopelícula para la eliminación de materia orgánica y nitrógeno (Development and modelling of a biofilm system for organic matter and nitrogen removal). Ph.D. diss., University of Cantabria, Santander (in Spanish)

16. Ji JY, Zheng K, Xing YJ, and Zheng P (2012) Hydraulic characteristics and their effects on working performance of compartmentalized anaerobic reactor. Bioresource Technol 116:47-52

17. Behzadian F, Yerushalmi L, Alimahmoodi M, and Mulligan CN (2013) Hydrodynamic characteristics and overall volumetric oxygen transfer coefficient of a new multi-environment bioreactor. Bioprocess Biosyst Eng 36:1043-1052

18. Zeng Y, Mu SJ, Lou SJ, Tartakovsky B, Guiot SR, and Wu P (2005) Hydraulic modelling and axial dispersion analysis of UASB reactor. Biochem Eng J 25(2):113-123

19. Nemade PD, Dutta SM, and Shankar HS (2010) Residence time distribution and oxygen transfer in a novel constructed soil filter. J Chem Technol Biot 85:77-84

20. Hartley K (2013) Tuning Biological Nutrient Removal Plants. IWA Publishing, London, UK

21. Levenspiel O (1999) Chemical reaction engineering, 3rd edn. J Wiley \& Sons, New York

22. Tang D, Jess A, Ren X, Bluemich B, and Stapf S (2004) Axial dispersion and wall effects in narrow fixed bed reactors: a comparative study based on RTD and NMR measurements. Chem Eng Technol 27(8):866873

23. Martin-Dominguez A, Tzatchkov VG, Martin-Dominguez IR, and Lawler DF (2005) An enhanced tanksin-series model for interpretation of tracer tests. J Water Supply Res T 54:435-448

24. Reichert P (1994) Aquasim - a tool for simulation and data-analysis of aquatic systems. Water Sci Technol 30(2):21-30

25. Henze M, Gujer W, Mino T, Matsuo T, Wentzel MC, Marais GVR, and Van Loosdrecht MCM (1999) Activated Sludge Model No.2d, ASM2d. Water Sci Technol 39:165-182

26. Water Environment Federation (2010) Nutrient Removal, WEF Manual of Practice No. 34. WEF Press, Alexandria, Virginia

27. Heertjes PM, and Van Der Meer RR (1978) Dynamics of liquid flow in an up-flow reactor-used for anaerobic treatment of wastewater. Biotechnol Bioeng 20(10):1577-1594

28. Lou SJ, Tartakovsky B, Zeng Y, Wu P, and Guiot SR (2006) Fluorescence-based monitoring of tracer and substrate distribution in an UASB reactor. Chemosphere 65:1212-1220

29. Ren TT, Mu Y, Yu HQ, Harada H, and Li YY (2008) Dispersion analysis of an acidogenic UASB reactor. Chem Eng J 142:182-189 